\title{
A hidden aortic rupture heralded by recurrent brain and retinal embolism
}

\author{
Andrea De Martino, MD, Giosuè Falcetta, MD, Giovanni Scioti, MD, and \\ Uberto Bortolotti, MD, Pisa, Italy
}

\footnotetext{
From the Section of Cardiac Surgery, Pisa University Hospital, Pisa, Italy. Disclosures: Authors have nothing to disclose with regard to commercial support.

Received for publication Sept 12, 2019; revisions received Sept 12, 2019; accepted for publication Oct 31, 2019; available ahead of print Jan 13, 2020.

Address for reprints: Andrea De Martino, MD, Sezione Autonoma di Cardiochirurgia Universitaria, Università di Pisa, Via Paradisa, 2, 56124 Pisa, Italy (E-mail: andrea.demartino@unipi.it). JTCVS Techniques 2020;1:15-6 2666-2507

Copyright (c) 2019 The Author(s). Published by Elsevier Inc. on behalf of The American Association for Thoracic Surgery. This is an open access article under the CC BY-NC-ND license (http://creativecommons.org/licenses/bync-nd/4.0/).

https://doi.org/10.1016/j.xjtc.2019.10.004
}

Atherosclerotic changes in the aortic wall of major arterial vessels represent an important risk factor of systemic embolism. Necropsy studies have demonstrated that complicated aortic plaques are variably associated with ischemic cerebral lesion that may be clinically silent. ${ }^{1}$ In the patient described here, the source of systemic embolism was identified in a previously undiagnosed calcific pseudoaneurysm of the noncoronary sinus.

A 65-year-old man experienced recurrent strokes with areas of brain and retinal ischemia (Figure 1, $A$ and $B$ ). After hospitalization, continuous monitoring excluded episodes of atrial fibrillation. Transthoracic and transesophageal 2-dimensional echocardiography (Figure 1, $C$ ) showed moderate aortic regurgitation and the presence of a $7 \times 5 \mathrm{~cm}$ saccular aneurysm of the noncoronary sinus that was confirmed by a computed tomography, which also showed gross calcification of the wall (Figure 1,D). At surgery, firm adhesions between the aortic root and the right atrium raised the suspicion of a pseudoaneurysm due to undiagnosed contained rupture (Figure 1,E); fragile calcific deposits (Figure 1,F) were considered the source of embolization. Repair of the pseudoaneurysm was obtained by

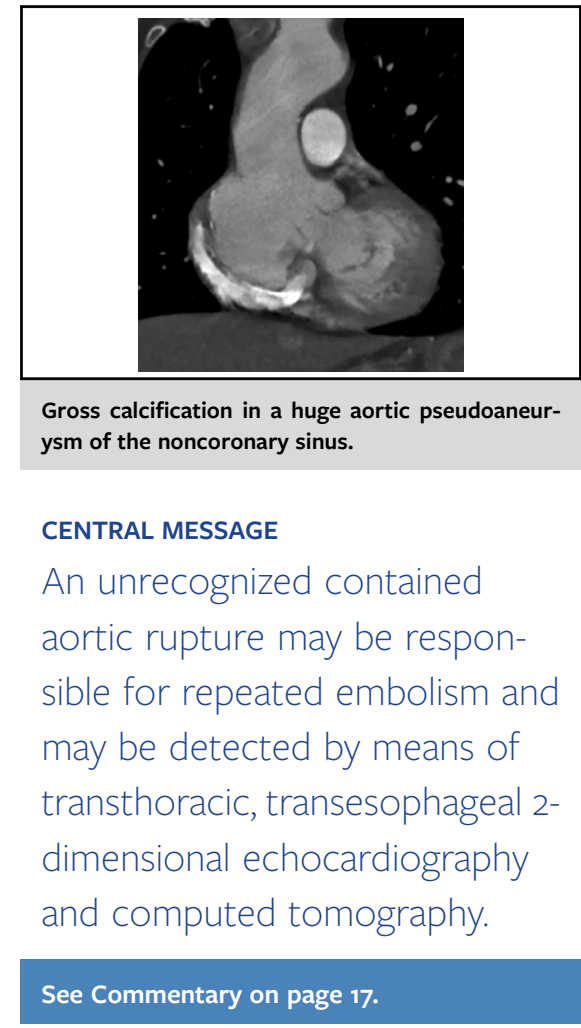

replacement of the noncoronary sinus using a polyethylene terephthalate patch. The patient recovered uneventfully with no further embolic episodes at 3-month follow-up.

\section{Reference}

1. Khatibzadeh M, Mitusch R, Stierle U, Gromoll B, Sheikhzadeh A. Aortic atherosclerotic, plaques as a source of systemic embolism. J Am Coll Cardiol. 1996;27: 664-9. 

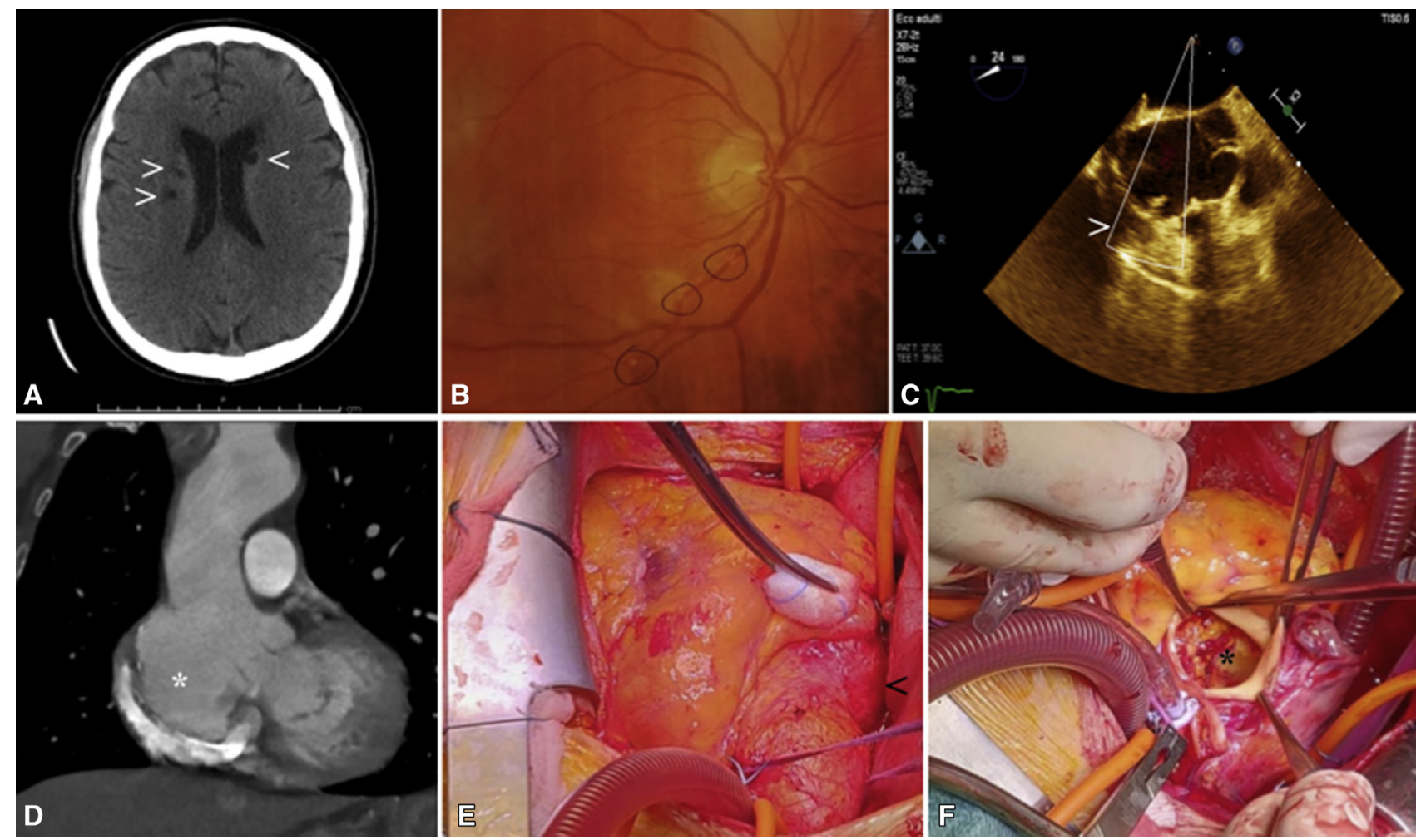

FIGURE 1. A 65-year-old man had recurrent strokes with areas of ischemia attributed to embolization. A, Areas of ischemia in the brain (arrows). B, Areas of ischemis in the retina (circles). C, Transesophageal echocardiography revealed a pseudoaneurysm of the aortic root (arrow). D, Computed tomography also revealed the pseudoaneurysm of the aortic root (asterisk). E, At surgery, fragile calcific deposits (arrow) confirmed the cause of embolization. F, Calcific deposits seen at surgery (asterisk). 